\title{
Non-adrenergic non-cholinergic inhibitory innervation shown by electrical field stimulation of isolated strips of human gall bladder muscle
}

\author{
M L McKirdy, H C McKirdy, C D Johnson
}

\begin{abstract}
Non-adrenergic non-cholinergic (NANC) inhibitory nerves have been described in all regions of the gastrointestinal tract, but have not been shown previously in the human gall bladder. Electrical field stimulation was used in the presence of various agonists and antagonists to show NANC inhibitory innervation in strips of human gall bladder muscle. Gall bladder strips were set up isometrically in an organ bath containing oxygenated Krebs's solution. Electrical field stimulation was applied at $10 \mathrm{~Hz}$, pulse width $0.3 \mathrm{~ms}$ and supramaximal voltage at intervals of 3 to 5 minutes. Of 60 strips that contracted in response to electrical field stimulation, 30 showed relaxation on electrical field stimulation in the presence of either carbachol (5-10 $\mu M)$ or else atropine $(0.5-2 \mu M)$ plus cholecystokinin octapeptide $(0 \cdot 01-0 \cdot 1 \mu \mathrm{M})$ or caerulein $(0 \cdot 1 \mathrm{nM})$ or histamine $(5-10 \mu \mathrm{M})$. In 22 strips this relaxation was not abolished by guanethidine $(2-5 \mu \mathrm{M})$ showing the NANC nature of this response. The NANC relaxation was abolished by L-nitroarginine $(100 \mu M)$ and this effect was partly reversible by $L$ arginine $(200 \mu M)$. All responses to electrical field stimulation were abolished by tetrodotoxin $(0 \cdot 2-2 \mu M)$. These results show for the first time a NANC inhibitory innervation in human gall bladder muscle. The probable neurotransmitter is nitric oxide.

(Gut 1994; 35: 412-416)
\end{abstract}

Non-adrenergic non-cholinergic (NANC) inhibitory nerves supply the smooth muscle of the upper, ${ }^{1}$ middle, and lower ${ }^{2}$ regions of the digestive tract of all mamalian species studied to date. These nerves have been shown to participate in relaxation of sphincters, in the descending inhibitory component of the peristaltic reflexes, and in receptive relaxation and accommodation of the stomach. ${ }^{12}$ Similar to the stomach, the gall bladder accommodates varying volumes with little change in pressure. ${ }^{3}$ It is unknown how much of this adaptation is a result of passive physical properties of the viscus and how much a result of active mechanisms reducing muscle tone.'

In the only previous study using electrical field stimulation in human gall bladder, no evidence for such NANC innervation was found. * Evidence for mediation of muscle relaxation, however, by NANC inhibitory nerve activity has been found in guinea pig gall bladder. ${ }^{5}$ We have reinvestigated the innervation of human gall bladder muscle strips using electrical field stimu- lation. Our findings suggest a sparse NANC inhibitory innervation. Preliminary findings have already been reported. ${ }^{67}$

\section{Methods}

COLLECTION OF TISSUE

Strips of gall bladder wall were taken from 138 surgically removed gall bladders. One hundred and thirty four gall bladders were removed for cholelithiasis and four normal gall bladders were removed during partial hepatectomy or pancreatic surgery. Macroscopically inflamed, or fibrosed gall bladders, and those severely distended by a mucocele were not accepted for the study. The gall bladder was removed within 15 minutes of ligation of the cystic artery. Immediately after removal, the gall bladder was opened longitudinally and a segment (about 2-3 $\mathrm{cm}^{2}$ ) was taken from the body of the gall bladder and placed in cooled oxygenated Krebs's solution in a vacuum flask for transport.

Segments of gall bladder wall were then pinned out flat in a Petri dish under cooled oxygenated Krebs's solution. ${ }^{8}$ The serosa and tunica adventitia were removed to leave the tunica muscularis with attached mucosa. In 10 specimens the mucosal layer was removed by scraping with a scalpel blade. Several strips (usually four) $10 \times 2-3 \mathrm{~mm}$ in size were obtained from each gall bladder and the remaining tissue was used for histological study. It was found that at $2^{\circ} \mathrm{C}$, the gall bladder muscle deteriorated within a few hours, unlike muscle strips from other regions of the digestive tract. ${ }^{9}$ Experiments were therefore started within one hour of removal of the gall bladder.

\section{RECORDING}

Each strip was suspended between parallel platinum electrodes in one of four identical $5 \mathrm{ml}$ organ baths. The bathing fluid was Krebs's solution ${ }^{8}$ at $37^{\circ} \mathrm{C}$ and gassed with $95 \%$ oxygen and $5 \%$ carbon dioxide. Isometric tension was monitored with a strain gauge transducer. The tension was displayed on a pen recorder (Devices, Letchworth Garden City, Herts). Each preparation was subjected to a maximum initial tension of $0 \cdot 1 \mathrm{~g}$.

\section{STIMULATION}

Electrical field stimulation was performed using rectangular pulses produced by a programmable digital stimulator. Tissues were stimulated at supramaximal voltage using 5-10 second trains 
of stimuli at $10 \mathrm{~Hz}$ and pulse width $0.3 \mathrm{~ms}$. Stimulation was performed once every three to five minutes.

\section{DRUGS $\bullet$ ND HORMONES}

Drugs and hormones were added in various concentrations to the organ bath. Values in the text show final bath concentration.

Drugs used were as follows: L-arginine (Sigma, St Louis, USA), atropine sulphate (Macfarlan Smith, Edinburgh, UK), caerulein (Sigma), carbachol (Macarthys Medical, Romford, UK), cholecystokinin octapeptide (Sigma), guanethidene sulphate (Ciba, Hersham, UK), histamine acid phosphate (BDH, Poole, UK), L-Ng-nitroarginine (Sigma), pentagastrin (ICI, Wilmslow, UK), and tetrodototoxin (Sigma). Adequate time was permitted after adding each agent for equilibration of the response before further testing.

\section{ANALYSIS OF DATA}

Tone, spontaneous contractions, and response (contraction or relaxation) to electrical field stimulation or to added agents were expressed in $\mathrm{g}$ tension or frequency/minute. Values are presented as mean (SD), but the important feature of these responses is their presence or absence as neurally mediated responses are generally held to be all or none phenomena. Statistical analysis was performed using Student's $t$ test.

\section{Results}

\section{SPONTANEOUS CONTRACTIONS}

Of 138 gall bladders studied, strips from 32 showed little or no spontaneous activity and little or no response to added agonists. These were considered non-viable and were excluded from the study. Of the remaining 106 viable specimens, strips from 92 showed spontaneous contractions at some stage during the experiment.

Spontaneous contractions were recorded as two different forms (Fig 1). Firstly, as low amplitude $(0 \cdot 18(0 \cdot 12) \mathrm{g}, \mathrm{n}=153)$ high frequency $(6.23(4 \cdot 7)$ per min, $n=111)$ rhythmic contractions, and secondly as high amplitude $(0.42(0.2)$ $\mathrm{g}, \mathrm{n}=15)$ low frequency $(0.69(0.51)$ per $\mathrm{min}$, $\mathrm{n}=15$ ) phasic contractions. These last phasic contractions were recorded in only 15 of the viable specimens and when present had the low amplitude contractions superimposed (Fig l).

TONE

Tone (sustained resting tension) was consistently low $(0.66(0.32) \mathrm{g}, \mathrm{n}=153)$. A greater value of spontaneous tension was attained only during phasic contractions (Fig 1) recorded in strips from 15 of 106 specimens.

\section{ELECTRICAL FIELD STIMULATION}

The response of gall bladder strips to electrical field stimulation was a contraction in 60 of 106 specimens. The remainder either did not respond or the response deteriorated rapidly. The response to electrical field stimulation was small $(0.32(0.15) \mathrm{g}, \mathrm{n}=60)$ compared with the tension after 10 minutes exposure to carbachol $5 \mu M(1.05(0.4) \mathrm{g}, \mathrm{n}=21)$ or to cholecystokinin $0.15 \mu \mathrm{M}(1.22(0.61) \mathrm{g}, \mathrm{n}=26)$ in the same set of strips. Larger responses to electrical field stimulation could be obtained by using a longer pulse width, but such responses may not be rapidly abolished by tetrodotoxin.'

\section{EFFECT OF ADDED AGENTS ON THE RESPONSE TO} ELECTRICAL FIELD STIMULATION

Of the 60 specimens that showed repeatable contractile responses to electrical field stimulation, strips from 30 showed relaxation of 0.23 $(0.08) \mathrm{g}$ to electrical field stimulation when the tone was raised by either firstly reducing (by 45$95 \%$ ) the contraction in response to electrical field stimulation with atropine $(0.5-2 \mu \mathrm{M})$ then adding cholecystokinin $(0 \cdot 01-0 \cdot 1 \mu \mathrm{M})$ (Fig 2) or caerulein $(0 \cdot 1 \mu \mathrm{M})$ or histamine $(5-10 \mu \mathrm{M})$; or secondly by using carbachol 5-10 $\mu \mathrm{M}$ (Fig 3) to raise the tone; it has been assumed that

A
$10 \min$

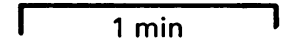

Figure 1: This shows tone and spontaneous activity. (A) The activity of a gall bladder strip approximately 10 minutes after setting up and during equilibration. Low amplitude high frequency rhythmic contractions are superimposed on high amplitude low frequency phasic contractions: $(B) a$ different strip after 45 minutes equilibration to show the interaction between high amplitude low frequency phasic contractions and the stimulation shown by the filled circles. Tension shown in grams. 
cholinergic receptors are desensitised at this concentration of carbachol. ' In strips from 22 of these gall bladders a relaxation response to electrical field stimulation remained $(0 \cdot 19(0.09)$ $\mathrm{g})$ in the presence of guanethidine $2-5 \mu \mathrm{M}$, showing the presence of a non-adrenergic noncholinergic response. In some of these strips the relaxation to electrical field stimulation seemed initially to have been abolished but with repeated stimulation a small relaxation that could be recorded at higher sensitivity developed over a period of up to 60 minutes in the presence of guanethidine (2-5 $\mu \mathrm{M}$ ) (Fig 4). All the responses to electrical field stimulation were abolished by tetrodotoxin $(0 \cdot 2-2 \mu \mathrm{M}, \mathrm{n}=5)$ (Fig 2$)$, or by lignocaine $(1 \mu \mathrm{M}, \mathrm{n}=5)$.

ROLE OF NITRIC OXIDE

The potent nitric oxide synthase inhibitor L-nitroarginine (L-NOARG) ${ }^{9}$ was used at two concentrations in eight specimens. At $10 \mu \mathrm{M}$ the NANC relaxation response to electrical field stimulation was abolished in one, reduced in three, and unaffected in four.

At $100 \mu \mathrm{M}$ L-NOARG the NANC response was abolished in all four strips tested. The effect of L-NOARG thus seems to be a dose dependent response. The effect of L-NOARG was partly reversible by exposure to L-arginine $(200 \mu \mathrm{M})$ (Fig 4).

\section{Discussion}

TONE, SPONTANEOUS CONTRACTIONS, AND RESPONSE TO ADDED AGENTS

Tone (spontaneous resting tension) in these studies was low in contrast with the finding of Mack and Todd. ${ }^{10}$ This may reflect the difference between a lightly loaded isotonic recording system and the isometric system 'that we used. Otherwise the results of these and previous studies" " are in substantial agreement with those of other workers ${ }^{410}$ regarding spontaneous activity and response to added agents. There is,
A

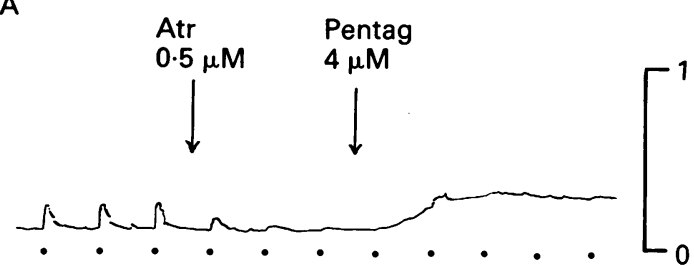

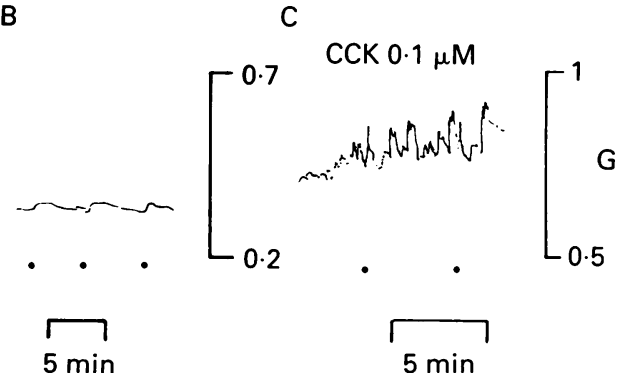

D
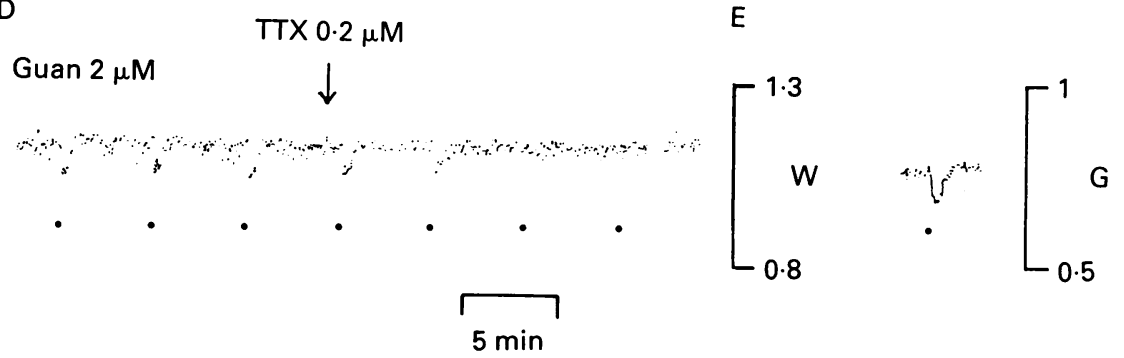

Figure 2: Analysis of the response to electrical field stimulation in a gall bladder strip. (A) The contraction to electrical feld stimulation (filled circles) is reduced by atropine (Atr). Pentagastrin (Pentag) causes a sustained contraction: $(B)$ about 5 minutes later at higher sensitivity recording. The increase in tone produced by this concentration of pentagastrin is insufficient to reverse the contraction to electrical field stimulation and show relaxation: $(C)$ about 10 minutes later, in the presence of added cholecystokinin octapeptide (CCK), which induces spontaneous activity and a further increase in tone: (D) about 25 minutes later in the presence of atropine, pentagastrin, cholecystokinin, and guanethidine (Guan, for 20 minutes). Relaxation to electrical field stimulation has developed and this is abolished by tetrodotoxin $(T T X):(E)$ recovery of the relaxant response to electrical field stimulation 10 minutes after washout (W) of all drugs.

A

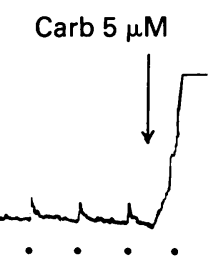

B

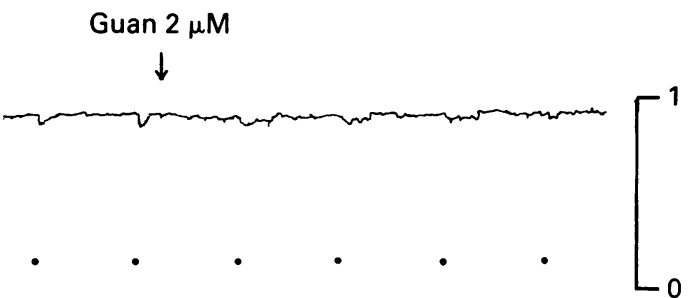

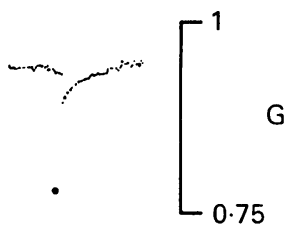

Figure 3: Shows the second technique used to show the relaxation to electrical field stimulation. (A) Contraction to electrical field stimulation followed by the addition of carbachol $(\mathrm{Carb})$, which increases tension: $(B)$ about 15 minutes later the carbachol induced increase in tension has fallen to a steady level. The response to electrical field stimulation is now a relaxation, which is reduced by guanethidine (Guan): (C) approximately 20 minutes later, a relaxant response has developed in the presence of guanethidine (shown at $4 \times$ greater sensitivity recording). 
Figure 4: Relaxant response to electrical field stimulation developing in the presence of atropine (Atr $1 \mu \mathrm{M})$, caerulein $($ Caer $0 \cdot 1 \mu M)$, and guanethidine (Guan 5 $\mu M)$. L-nitroarginine $(L-N O A R G 10 \mu M)$ has no effect on the developing response. The response is abolished, however, by $L-N O A R G 100 \mu M$, and recovery of the response is rapid in L-arginine $(L-A R G)$.

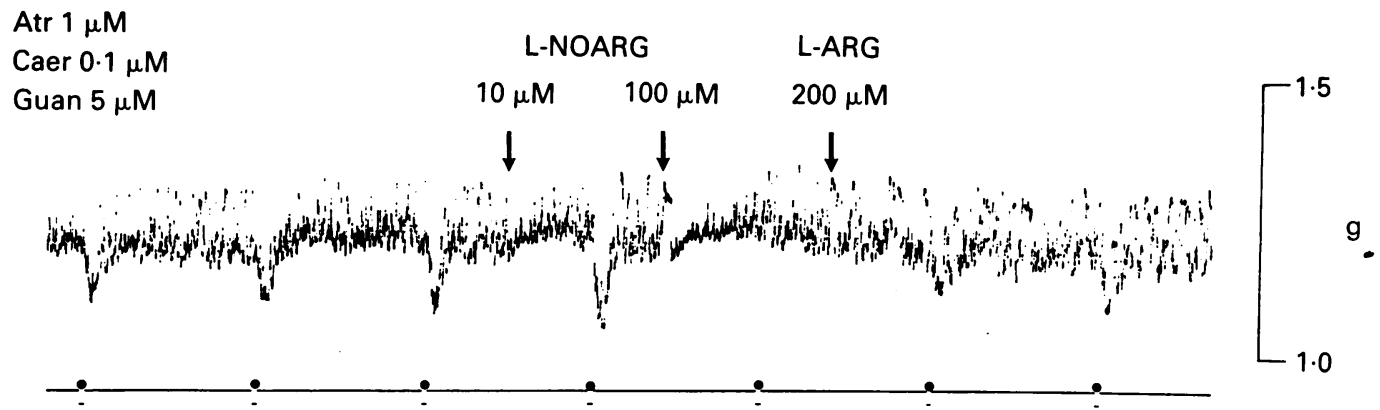

$3 \min$

however, one important difference. This study has investigated neurally mediated responses to electrical field stimulation in human gall bladder strips. The results provide the first evidence of non-adrenergic, non-cholinergic relaxant responses in human gall bladder.

\section{NANC RESPONSE}

Our results show that a small component of the relaxant response to electrical field stimulation remains detectable during cholinergic blockade by atropine (or after desensitisation of cholinergic receptors with carbachol) and adrenergic blockade with guanethidine. This is the first clear evidence for the existence of such non-adrenergic non-cholinergic inhibitory nerves in human gall bladder. Several questions arise, however, which need discussion.

Firstly, NANC inhibitory responses were found in only 22 of 106 specimens of gall bladder muscle. All but four of these gall bladders were removed for gall stone disease although comparatively healthy gall bladders were selected. Nevertheless, it has been shown (unpublished data) that nerve responses are influenced by the severity of inflammation and fibrosis and it is possible that NANC responses were lost in some strips as a result of inflammation. Moreover, the distribution density of ganglion cells in the gall bladder is considerably less than in the enteric plexuses elsewhere in the gastrointestinal tract and NANC neurones may be quite sparsely distributed leaving some strips comparatively deficient in NANC neurones.

We could detect NANC inhibitory responses in the human gall bladder whereas Feeley et $\mathrm{al}^{4}$ could not. There is no clear explanation for this, but the two studies differ in several ways. The stimulus parameters used are different in the two studies. Probably the most important difference is that we used a short pulse width of $0.3 \mathrm{~ms}$. We have confirmed that with such pulse widths, responses to electrical field stimulation are rapidly abolished by the potent neurotoxin tetrodotoxin, which confirms that the response is neurally mediated. In contrast, responses to longer pulse widths may not be rapidly abolished by tetrodotoxin.' Short pulse widths may be most suitable for activating NANC nerves, as found in human trigone. ${ }^{12}$ In our study we used guanethidine to achieve a presynaptic adrenergic blockade. Feeley $e t a l^{4}$ used propranolol, which acts postsynaptically. It has previously been seen that NANC responses often develop during exposure to guanethidine. ${ }^{13} \mathrm{We}$ have confirmed that it may be necessary to wait some time to see this phenomenon. Finally the high concentration of propranolol used by Feeley et $\mathrm{al}^{4}$ would be expected to have a powerful local anaesthetic activity. ${ }^{14}$ This might well have impaired the ability of the NANC conducting nerve fibres to respond to electrical field stimulation. This view is reinforced by the finding that D-propranolol, which has almost exclusively local anaesthetic activity, reduced the relaxation to electrical field stimulation though not as effectively as DLpropranolol $(100 \mu \mathrm{M})$ which has beta blocking and local anaesthetic activity. ${ }^{15}$

We conclude from our findings that the human gall bladder seems to have a sparse NANC inhibitory innervation as well as a cholinergic excitatory innervation and a potentially functional inhibitory noradrenergic innervation."

\section{NITRIC OXIDE}

L-nitroarginine reduced or abolished the NANC relaxation in a dose dependent manner, which suggests that nitric oxide participates in NANC transmission in the human gall bladder. This confirms a preliminary report ${ }^{16}$ of nitric oxide participation in the relaxation of biliary tract smooth muscle, and is consistent with recent histochemical evidence showing NADPH diaphorase containing neurones in gall bladders of several species including humans. ${ }^{17}$ It is also possible that nitric oxide might participate in the NANC relaxation of the sphincter of Oddi. ${ }^{18}$ The participation of nitric oxide in the NANC relaxation of other human sphincters ${ }^{19}$ and nonspincter ${ }^{9}$ muscle has already been shown.

It is concluded that the human gall bladder may receive a sparse NANC inhibitory innervation. Further studies are required to elucidate the NANC inhibitory response and the possible role of nitric oxide in mediating this response in biliary tract smooth muscle.

We are grateful to Dr R W Marshall for the use of apparatus, to $\operatorname{Dr} M \mathrm{~J}$ Lewis for use of drugs and for constructive suggestions,

and to Mr B A Taylor for his help during early experiments. Presented in part at the British Society for Gastroenterology
September 1991, and the Physiological Society in December 1991 .

1 McKirdy HC. Novel autonomic neurotransmitters and upper gastrointestinal function. Pharmacol Ther 1988; 38: 429-52.

2 Taylor GS, Bywater RAR. Novel autonomic neurotransmitters and intestinal function. Pharmacol Ther 1988; 40 401-38. 
3 Ryan J, Cohen S. Gallbladder pressure-volume response to gastrointestinal hormones. Am f Physiol 1976; 230: 1461-5.

4 Feeley TM, Clanachan AS, Scott GW. Contractility of human gallbladder muscle in vitro. Aliment Pharmacol Ther 1987; 1 : 607-16.

5 Al-Hassani $\mathrm{MH}$, Davidson JS. The role of the non-cholinergic, non-adrenergic inhibitory nerves in the regulation of the guinea-pig gallbladder. $\mathcal{F}$ Physiol (Lond) 1979; 292: 48P.

6 McKirdy ML, Johnson CD. Non-adrenergic non-cholinergic inhibitory innervation in human gallbladder muscle. Gut 1991; 32: A1209.

7 McKirdy ML, Johnson CD. Non adrenergic, non cholinergic (NANC) inhibitory innervation of the isolated human NANC) inhibitory innervation of the isolated human
gallbladder. 7 Physiol (Lond) 1992; 446:526P.

8 Mackenna BR, McKirdy HC. Peristalasis in the rabbit distal colon. F Physiol (Lond) 1972; 220: 33-54

9 Magi CA, Barbanti G, Turini D, Giuliani S Effect of Maggi CA, Barbanti G, Turini D, Giuliani S. Effect of
Ng-monomethyl L-arginine (L-NMMA) and Ng-nitro $\mathrm{L}$-arginine (L-NOARG) on non-adrenergic non-cholinergic relaxation in the circular muscle of the human ileum. $\mathrm{Br} \mathcal{F}$ Pharmacol 1991; 103: 1970-2.

10 Mack AJ, Todd JK. A study of human gallbladder muscle in vitro. Gut 1968; 9: 546-9.

11 McKirdy HC, Marshall RW, Taylor BA. In vitro studies on the innervation of human gallbladder muscle. $f$ Physiol (Lond) 1988; 412: 56P

12 Speakman MJ, Walmsley D, Brading AF. An in vitro pharma- cological study of the human trigone - a site of nonadrenergic, non cholinergic neurotransmission. $\mathrm{Br} \mathcal{F}$ Uro 1988; 61: 304-9.

13 Gillespie JS. The rat anococcygeus muscle and its response to nerve stimulation and to some drugs. BrF Pharmacol 1972; 45: 404-16

14 Barrett AM, Cullum VA. The biological properties of the optical isomers of propronolol and their effects on cardiac arrhythmias. Br F Pharmacol 1968; 34: 43-55.

15 McKirdy HC, McKirdy ML, Marshall RW, Taylor BA. In vitro evidence for a possible non-adrenergic inhibitory innervation of human gallbladder muscle. $f$ Physiol (Lond) 1990; 424: 71P.

16 Guarner F, Molero X, Moncada S, Malagelada J-R. An $\mathrm{L}$-arginine/nitric oxide pathway regulates gallbladder L-arginine/nitric oxide pathway regula

17 Talmage EK, Mawe GM. NADPH-diaphorase and VIP are co-localised in neurons of gallbladder ganglia. 7 Auton Nerv co-localised in neuron

18 McKirdy HC, Marshall RW, Griffin P. Effect of drugs, hormones and electrical field stimulation on isolated muscle strips from human choledochoduodenal junction. $Q \mathcal{F} \operatorname{Exp}$ Physiol 1987; 72: 215-25.

19 McKirdy ML, McKirdy HC, Marshall RW, Lewis MJ Evidence for the involvement of nitric oxide in the nonadrenergic non-cholinergic relaxation of sphincter muscle strips in vitro. F Physiol (Lond) 1992; 446: 592P. 